\title{
The Effect of Hormone Replacement Therapy on Oxidized Low Density Lipoprotein Levels and Paraoxonase Activity in Postmenopausal Women
}

\author{
Ata Topçuoğlu, Hafize Uzun, ${ }^{1}$ Seval Aydin, ${ }^{1}$ Nurhan Kahraman, ${ }^{2}$ Suphi \\ Vehid, ${ }^{3}$ Gorkem ZeYBeK ${ }^{2}$ and Deniz TopÇUOĞLU ${ }^{2}$ \\ Department of Obstetrics and Gynecology A.İ.B. ̈̈. İzet Baysal Faculty of \\ Medicine, Bolu, \\ ${ }^{I}$ Department of Biochemistry, ${ }^{2}$ Department of Obstetrics and Gynecology and \\ ${ }^{3}$ Department of Public Health, Cerrahpassa Faculty of Medicine, Istanbul \\ University, Istanbul, Turkey
}

Topçuoğlu, A., Uzun, H., Aydin, S., Kahraman, N., Vehid, S., Zeybek, G. and TopçuoĞLu, D. The Effect of Hormone Replacement Therapy on Oxidized Low Density Lipoprotein Levels and Paraoxonase Activity in Postmenopausal Women. Tohoku J. Exp. Med., 2005, 205 (1), 79-86 — Oxidized low-density lipoproteins (oxLDL) are involved in initiation of atherosclerosis. Paraoxonase 1 (PON1), the isoenzyme of PON, is located on high-density lipoprotein (HDL) and protects against the oxidative modification of both HDL and LDL by hydrolysing lipid peroxides. Postmenopausal women have a higher risk of cardiovascular events compared with premenopausal women. The aim of this clinical study was to evaluate the effects of hormone replacement therapy (HRT) on oxLDL and PON1 activity in menopausal status. The subjects included 45 healthy postmenopausal women, aged 43 to 57 years, and 30 premenopausal women with regular cycles, aged 31 to 40 years. None of the participating women had a history of hypertension, diabetes mellitus or medications known to affect the cardiovascular system. Twenty five of the postmenopausal women received conjugated estrogens at dose of $0.625 \mathrm{mg} /$ day per oral (P.O.) and medroxyprogesterone acetate (MPA) (1 mg/d P.O.) for 10 days. Twenty of the postmenopausal women received 17-beta estradiol ( $2 \mathrm{mg} /$ day) and norethysterone acetate (NETA) (5 $\mathrm{mg} /$ day P.O.) for 10 days. Fasting blood samples were taken from premenopausal women (baseline) and postmenopausal women after HRT of 6 months to determine serum malondialdehyde (MDA), oxLDL, and PON1 activity. After 6-month therapy, MDA and oxLDL levels showed a statistically significant reduction in the treated groups versus baseline $(p<$ $0.05)$, whereas PON1 activities were increased $(p<0.05)$. Increase in oxidative status may be one of the factors leading to reduction in PON1 activity and increased oxLDL in menapouse. HRT may be effective on oxidative stress and lipoprotein metabolism in apparrently healthy postmenopausal women. _ hormone replacement therapy; paraoxonase; oxidized low-density lipoprotein (oxLDL); malondialdehyde (MDA); oxidative stress

(C) 2005 Tohoku University Medical Press

Received July 9, 2004; revision accepted for publication November 16, 2004.

Address for reprints: Ass. Prof. Dr. Hafize Uzun, Department of Biochemistry, Cerrahpasa Faculty of Medicine, Istanbul University, Istanbul, Turkey.

e-mail: huzun59@hotmail.com. 
Among risk factors for coronary heart disease (CHD) identified by epidemiological studies, a low plasma high-density lipoprotein (HDL) level is one of the most important. For any given low-density lipoprotein (LDL) concentrations, the HDL concentration is inversely correlated with the risk of CHD and stroke (Mackness et al. 2002). The antiatherosclerotic effects of estrogen were attributed principally to the hormone's effects on serum lipid concentrations. Estrogeninduced alterations in serum lipids account for only approximately one third of the observed benefits of estrogen (Nelson et al. 1991; Lazar et al. 1999). The leading cause of death among women in developed nations is CHD, the incidence of which increases substantially after menopause. Estrogen increases vasodilatation and inhibits the response of blood vessels to injury and the development of atherosclerosis. Estrogen-induced vasodilatation occurs 5 to 20 minutes after estrogen has been administered and is not dependent on changes in gene expression; this action of estrogen is sometimes referred to as "nongenomic" (Mendelson and Karas 1999).

Paraoxonase (PON)1 is a calcium-dependent enzyme with a molecular mass of $43 \mathrm{Kda}$ ( 354 amino acids) and in serum is exclusively located on HDL (Mackness et al. 1996). PON1 is synthesized and secreted by liver. PON1 tightly binds to HDL subfractions that also contain apoA-1 and apoJ or clusterin and it has the capacity to protect LDL against oxidation. Oxidation of LDL appears to play an important role in the development and progression of the atherosclerotic lesion (Itabe 2003). PON1 inhibits HDL and LDL oxidation and preserves their function (Mackness et al. 1996; Aviram et al. 1998). The purpose of this study was to investigate the effects of hormone replacement therapy (HRT) on PON1 activity, oxLDL and lipoprotein levels in healthy postmenopausal women.

\section{Materials ANd Methods}

This study included 45 healthy women with spontaneous natural menopause and with normal gynecologic examination, composed of cervical smear, mammography, and gynecologic ultrasonography. At the beginning of the study, a complete history, physical examination, laboratory evaluation (biochemistry and blood panel), and electrocardiography were done for each participant. The study was approved by the Ethics Commitee of Cerrahpasa Medical Faculty, and each patient was given informed consent. All patients agreed not to alter their diet and exercise regiments during the study period. The inclusion criteria: (1) a naturally occurring menopause after 40 years of age; (2) menopause must have occurred at least 1 year prior to inclusion in the study; (3) a high follicle stimulating hormone (FSH) $>40 \mathrm{IU} /$ liter and a low estradiol (E2) < $10 \mathrm{pg} / \mathrm{ml}$; (4) presence of climacteric symptoms such as hot flushes, palpitations and night sweats. Exclusion criteria were women with significant systemic illnesses such as renal failure, liver impairment, cardiovascular disease, acute or chronic infections, neoplastic diseases, gastrointestinal diseases, diabetes and alcoholism. Patients were followed up and monthly evaluated for compliance.

Most subjects in the same age range entered the database by a random selection of employees in the hospital. All women were normotensive (blood pressure < $140 / 90 \mathrm{mmHg}$ ). Subjects with other risk factors for atherosclerosis (LDL > $130 \mathrm{mg}$, diabetes mellitus, BMI > 27 , or smoking), and subjects having signs or symptoms of atherosclerotic vascular disease and other endocrine diseases or alcoholism were not included. Premenopausal women $(n=30)$ were not using oral contraceptives and were tested during 3rd-8th day of their menstrual cycle.

Measurements of brachial artery blood pressures in the patients referred to our clinic due to high blood pressure (diastolic pressure $>90 \mathrm{mmHg}$ ) were obtained in our outpatient clinic by a nurse with a mercury sphygmomanometer which was standardized in accordance with the approval of American and British Hypertension Society and World Health Organisation (1992). In choosing two different HRT regimens, we aimed to compare the effects of conjugated estrogens with $17 \beta$ estrogen and MPA with NETA. After the first testing, 25 of postmenopausal women (Group 1) received conjugated estrogens at dose of $0.625 \mathrm{mg}$ P.O. per day and medroxyprogesterone acetate (MPA) $5 \mathrm{mg}$ P.O. for 10 days. 20 of postmenopausal women (Group 2) received 17-beta estradiol $2 \mathrm{mg}$ P.O. per day and norethysterone acetate (NETA) $5 \mathrm{mg}$ P.O. for 10 days. To minimize the effects of the medroxyprogestrone, repeated daily laboratory measurement were done before the second course of medroxyprogestrone on samples obtained while participants 
were fasting.

\section{Sample collection}

Blood was taken after $12-14 \mathrm{~h}$ of fasting in the morning. Serum was drawn after at least 30 minutes of clotting by centrifugation at $2500 \mathrm{~g}$ for 15 minutes. Each sample was divided into 4 aliquots; 1rst aliquot was used directly for the measurements of hormones, cholesterol, triglycerides, HDL-cholesterol and glucose. Second aliquot was kept in $-80^{\circ} \mathrm{C}$ until analysis of serum PON1 activity within 2 weeks; other two aliquots were stored in $-80^{\circ} \mathrm{C}$ for estimation of serum MDA and oxLDL at a later date (within a month). All parameters were analyzed in all samples together in a single batch, after we had finished our protocol (control and patient samples were analyzed in the same batch).

\section{Assay of TBARS}

Lipoperoxidation was ascertained by the formation of MDA, which was estimated by the modified thiobarbituric acid method, described by Buege and Aust (1978). TBARS concentration was calculated using $1.56 \times 10^{-5}$ $\mathrm{M}^{-1} \mathrm{~cm}^{-1}$ as $\mathrm{mol} /$ liter extinction coefficient. The results were expressed as micromoles ( $\mu \mathrm{mol} / \mathrm{liter})$. The coefficients of intra-and inter-assay variations for MDA assays were $4.1 \%(n=12)$ and $5.4 \%(n=11)$, respectively.

\section{Assay of PON1 Activity}

PON1 activity was assayed using synthetic paraoxon (diethyl-p-nitrophenyl phosphate) as a substrate. PON1 activity was determined by measuring the initial rate of substrate hydrolysis to p-nitrophenol, whose absorbance was monitored at $412 \mathrm{~nm}$ in the assay mixture containing $2.0 \mathrm{mM}$ paraoxon, $2.0 \mathrm{mM} \mathrm{CaCl} 2$ and $20 \mu \mathrm{L}$

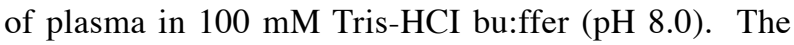
blank sample containing incubation mixture without serum was run simultaneously to correct for spontaneous substrate breakdown. The enzyme activity was calculated from E412 of p-nitrophenol (18.290 per M/cm) and was expressed as U/liter; $1 \mathrm{U}$ of enzyme hydrolyses 1 nmoles of paraoxon/min (Saha et al. 1991; Hasselwander et al. 1999). The coefficients of intra and inter-assay variations for PON1 activities were 3.6\% $(n=12)$ and $4.3 \%(n=11)$, respectively.

\section{Assay of oxLDL}

The concentration of oxLDL in serum was measured by sandwich ELISA procedure using the murine monoclonal antibody, mAb-4E6 as capture antibody bound to microtitration wells, and peroxidase conjugated antiapolipoprotein B antibody recognizing oxLDL bound to the solid phase (Mercodia Oxidized LDL ELISA, Uppsala, Sweden). The coefficients of intra and interassay variations for oxLDL were $3.9 \%(n=8)$ and $7.5 \%(n$ $=6)$, respectively.

Serum insulin levels were measured by radioimmunoassay using commercial kit (DSL-1600, Finleyville, PA, USA). Serum E2 and FSH were evaluated by electrochemiluminescence immunassay (ECLIA) (Roche, Basel, Switzerland). Serum glucose, total cholesterol (T-C) and TG were measured by enzymatic methods using commerciall kits (Olympus, Hamburg, Germany) on Olympus AU800 analyzer. HDL cholesterol (HDL-C) was measured after precipitation of the apo B-containing lipoproteins with phosphotungistic acid. LDL cholesterol (LDL-C) was calculated using Friedewald formula (Friedewald et al. 1972).

\section{Statistical analysis}

Statistical comparisons between groups were made by the paired $t$-test. The data were given as means \pm S.D. The level of statistical significance was taken as $p<0.05$.

\section{RESUlts}

General characteristics were given in Table 1. There were no significant differences between premenopausal and postmenopausal women with regards to systolic blood pressure, glucose and insulin levels. However, there were significant differences $(p<0.05)$ in BMI, diastolic blood pressure, $\mathrm{FSH}, \mathrm{E}_{2}$, lipids, MDA, PON1 and oxLDL.

Serum lipid parameters, MDA, oxLDL and PON1 levels in postmenopausal women before and six months after HRT were given in Table 2. After 6 months of HRT, serum MDA, oxLDL and PON1 levels were found to be significantly different $(p<0.05)$ in postmenopausal women who used two different HRT regimens stated before. In the first group where the subjects had conjugated estrogen and MPA had higher PON1 activity compared to the second group where the subjects had 17 beta estradiol and NETA. However, in the second group, MDA levels showed a steeper increase and the oxLDL levels showed more decline compared to the first group, yet not statistically significant. 
TABLE 1. Basaline clinical and biological data of the groups

\begin{tabular}{lcc}
\hline & Premenopausal women & Postmenopausal women \\
& $n=30$ & $n=45$ \\
\hline Age & $35.2 \pm 2.41$ & $48.91 \pm 4.25^{*}$ \\
Age at menopause & - & $4.65 \pm 2.20$ \\
BMI $\left(\mathrm{Kg} / \mathrm{m}^{2}\right)$ & $23.18 \pm 1.29$ & $26.25 \pm 1.67^{*}$ \\
Clinical SBP $(\mathrm{mmHg})$ & $124.57 \pm 5.74$ & $126.53 \pm 8.65$ \\
Clinical DBP $(\mathrm{mmHg})$ & $81.50 \pm 2.32$ & $85.18 \pm 4.93^{*}$ \\
Glucose $(\mathrm{mg} / 100 \mathrm{ml})$ & $92.37 \pm 6.77$ & $91.78 \pm 8.37$ \\
İnsulin $(\mathrm{U} / \mathrm{ml})$ & $13.75 \pm 1.60$ & $14.25 \pm 1.28$ \\
FSH $(\mathrm{mIU} / \mathrm{ml})$ & $5.85 \pm 1.26$ & $64.24 \pm 17.32^{*}$ \\
E $(\mathrm{pg} / \mathrm{ml})$ & $73.80 \pm 15.74$ & $5.91 \pm 1.80^{*}$ \\
Total-C $(\mathrm{mg} / 100 \mathrm{ml})$ & $189.23 \pm 17.94$ & $213.67 \pm 31.65^{*}$ \\
HDL-C $(\mathrm{mg} / 100 \mathrm{ml})$ & $52.57 \pm 8.62$ & $47.20 \pm 10.77^{*}$ \\
LDL-C $(\mathrm{mg} / 100 \mathrm{ml})$ & $117.77 \pm 19.12$ & $138.71 \pm 26.08^{*}$ \\
Triglycerides $(\mathrm{mg} / 100 \mathrm{ml})$ & $96.83 \pm 14.47$ & $135.67 \pm 67.03^{*}$ \\
MDA $(\mu \mathrm{mol} / \mathrm{liter})$ & $2.81 \pm 0.25$ & $4.82 \pm 0.39^{*}$ \\
OxLDL $(\mathrm{U} / \mathrm{liter})$ & $44.57 \pm 8.94$ & $54.13 \pm 8.34^{*}$ \\
PON1 $(\mathrm{U} / \mathrm{liter})$ & $74.06 \pm 18.19$ & $51.47 \pm 7.70^{*}$ \\
\hline
\end{tabular}

${ }^{*}$ Comparison between pre- and postmenopausal women, $p<0.05$.

TABLE 2. Serum lipid parameters, MDA, oxLDL and PON1 levels in postmenopausal women before and after HRT

\begin{tabular}{lccc}
\hline & MPA & NETA & Total \\
& $n=25$ & $n=20$ & $n=45$ \\
\hline Total-C & $204.1 \pm 30.0 /$ & $225.7 \pm 30.1 /$ & $213.7 \pm 31.7 /$ \\
Pre/ Post-treatment $(\mathrm{mg} / 100 \mathrm{ml})$ & $178.6 \pm 10.7^{*}$ & $191.6 \pm 21.1^{*}$ & $184.4 \pm 17.2^{*}$ \\
HDL-C & $45.7 \pm 10.6 /$ & $49.1 \pm 11.0 /$ & $47.2 \pm 10.8 /$ \\
Pre/ Post-treatment $(\mathrm{mg} / 100 \mathrm{ml})$ & $53.2 \pm 7.6^{*}$ & $56.6 \pm 8.2$ & $54.8 \pm 8.0^{*}$ \\
LDL-C & $131.7 \pm 24.9 /$ & $147.5 \pm 25.5 /$ & $138.71 \pm 26.08 /$ \\
Pre/ Post-treatment $(\mathrm{mg} / 100 \mathrm{ml})$ & $102.8 \pm 13.6^{*}$ & $112.7 \pm 21.2^{*}$ & $107.2 \pm 17.9^{*}$ \\
Triglycerides & $133.5 \pm 62.0 /$ & $138.4 \pm 74.4 /$ & $135.67 \pm 67.1 /$ \\
Pre/ Post-treatment $(\mathrm{mg} / 100 \mathrm{ml})$ & $115.2 \pm 35.2$ & $113.5 \pm 37.0$ & $114.4 \pm 35.6$ \\
MDA & $4.7 \pm 0.4 /$ & $4.9 \pm 0.4 /$ & $4.82 \pm 0.4 /$ \\
Pre/ Post-treatment $(\mu \mathrm{mol} / \mathrm{liter})$ & $4.0 \pm 0.4^{*}$ & $3.6 \pm 0.3^{*}$ & $3.8 \pm 0.4^{*}$ \\
oxLDL & $54.9 \pm 8.5 /$ & $53.1 \pm 8.3 /$ & $54.13 \pm 8.34 /$ \\
Pre/ Post-treatment $(\mathrm{U} / \mathrm{liter})$ & $47.9 \pm 4.0^{*}$ & $44.8 \pm 4.4^{*}$ & $46.6 \pm 4.4^{*}$ \\
PON1 & $51.5 \pm 6.7 /$ & $51.4 \pm 9.0 /$ & $51.47 \pm 7.7 /$ \\
Pre/ Post-treatment $(\mathrm{U} /$ liter $)$ & $73.9 \pm 11.2^{*}$ & $67.4 \pm 10.0^{*}$ & $71.0 \pm 11.1^{*}$ \\
\hline
\end{tabular}

${ }^{*}$ Comparison of parameters before and after HRT in postmenopausal women, $p<0.05$ 


\section{Discussion}

Menopause is associated with a significant increase in the prevelance of cardiovascular disease in women (Ryan 1976). HRT is one of the most frequently prescribed treatments in the modern practice of gynecology. HRT in postmenopausal women is beneficial in terms of reducing vasomotor symptoms, osteoporosis and cardiovascular risk (Bittner 1994). In postmenopausal women with an intact uterus, estrogen therapy alone, unopposed by progesterone, is associated with endometrial proliferation, hyperplasia and eventually endometrial cancer (Di Spiezio Sardo and Radhakrishnan 2004). On the other hand, long term compliance to HRT is not as good as it should be due to a number of issues of concern including the potentially increased risk of breast cancer (Colditz et al. 1995). HRT is also believed to cause weight gain by postmenopausal women (Nachtigall 1990).

In 2002, Women's Health Initiative (WHI) (Rossouw et al. 2002) randomized controlled trial, participants received conjugated equine estrogens, $(0.625 \mathrm{mg} /$ day $)$, plus medroxyprogesterone acetate, $(2.5 \mathrm{mg} /$ day $)$, in single tablets or placebo. Overall health risks exceeded benefits from use of combined estrogen plus progestin for an average 5.2-year follow-up among healthy postmenopausal US women. All-cause mortality was not affected during the trial. The risk vs. benefit profile found in this trial is not consistent with the requirements for a viable intervention for primary prevention of chronic diseases, and the results indicate that this regimen should not be initiated or continued for primary prevention of CHD.

Many studies have focused on the relationship between the lipid and lipoprotein balance in climacteric women and have shown that menopause is accompanied by elevated total cholesterol (TC), LDL-C and triglyceride (TG) concentrations. This singular association is helpful to explain why cardiovascular morbidity and mortality are high in climacteric women (Ettinger 1989; Matthews et al. 1989; Lobo 1990). However, Warren and Halpert (2004) stated that progestins, in contrast to estrogens, have variable effects on lipoproteins based on their androgenicity. More androgenic progestins tend to lower HDL levels to a greater degree than do the less androgenic progestins. The two types of progestins we used for HRT are those derived from 19-norestosterone and 17-hydroxyprogesterone. The former are the most potentially androgenic, while the latter have a little androgenicity. Medroxyprogesterone is the most commonly prescribed progestin in the USA and is derived from 17-hydroxyprogesterone. Recently, micronised progesterone has become available which has less adverse effects on the lipid metabolism. Therefore, when the pros and cons are added, as with the new progestin products available, the HRT usage is sensible in terms of CHD risks.

Many studies in the literature confirm that the association of age and menopause, and consequently the association of age of onset and duration of climacteric period, are risk factors for vascular and coronary diseases (Van der Schouuw et al. 1996), like observed in healthy subjects presenting elevated TC, and LDL-C concentrations (Kannel et al. 1976; Eaker et al. 1993). Menopause has marked effects on the circulating levels of lipids and lipoproteins, leading to an increased atherogenic pattern (Campos et al. 1988; The Writing Group for the PEPI Trial 1995; de Aloysio et al. 1999). Previously Oral and Özbaşar (2003) reported that a daily dose of 25 mg monofluorophosphate had no significant adverse changes in the lipids and lipoproteins in postmenopausal women. When added to HRT with a dose of $25 \mathrm{mg}$ daily, it neither attenuated lipid profiles of women taking combined HRT, nor potentiated the effect of HRT. Our results confirm the beneficial effects of HRT on lipid and lipoprotein metabolism. Beneficial changes in the lipid profile are due to HRT, indicating that hormones significantly control lipid metabolism, which attenuates endothelial injury and inhibits atherosclerosis. In the present study we examined the oxidant and antioxidant status to evaluate the oxidative stress in postmenopausal women and compared with premenopausal women. Regarding MDA which is considered as a marker of lipid peroxidation (reactive oxygen species - 
[ROS]), our findings indicated that oxidative stress increased in postmenopausal women, compared with premenopausal women.

Considering with oxLDL, oxidative stress increased significantly in postmenopausal women compared to premenopausal women. We observed that the antioxidant capacity of the PON1 activity in postmenopausal women declined. The influence of oxidative stress in postmenopausal women is studied by many authors (Leal et al. 2000; Bureau et al. 2002). However, the results are controversial. They reported that the higher oxidative stress in postmenopausal women was due to the imbalance between oxidants and antioxidant mechanisims. Increase in oxidants and decrease in antioxidant capacity is the main cause of atherosclerosis.

Sutherland et al. (2001) suggested that HRT with a conjugated equine estrogen and medroxyprogesterone acetate may increase serum PON1 arylesterase activity in postmenopausal diabetic women, greatest increase seen in women with lower baseline levels and in those who experience an increase in HDL cholesterol levels. The magnitude of this HRT-induced increase in serum PON1 arylesterase activity appears to be clinically relevant because the activity in diabetic postmenopausal women during treatment nearly reached levels as high as their healthy counterparts. PON1 hydrolyzes lipid peroxides in lipoproteins and atherosclerotic lesions, where they may have atherogenic properties. Thus, it is conceivable that an HRT-induce increase in serum PON1 activity is associated with a delay in the formation and progression of atherosclerotic disease in postmenopausal diabetic women.Our results confirm this findings in healthy postmenopausal women. Beneficial changes in the lipid profile are due to HRT, indicating that hormones significantly control lipid metabolism, and thus attenuates endothelial injury and inhibits atherosclerosis.

We were not able to find any data in the literature regarding the antioxidant influence of MPA and NETA on MDA, oxLDL, or PON1 activity in menopause. In the first group where the subjects had conjugated estrogen and MPA had higher
PON1 activity compared to the second group where the subjects had 17 beta estradiol and NETA. However, in the second group, MDA levels showed a steeper increase and the oxLDL levels showed more decline compared to the first group, yet not statistically significant. Due to our findings we believe that the two different HRT regimens are not preferable over one other.

The significant increase of PON1 in the women receiving HRT suggests that only responders experience the cardioprotective and antioxidant effects of HRT. It is proposed that metal-catalyzed oxidation may be a primary factor to cause the decrease of HDL-associated PON1 activity under oxidative stress, and radicals-induced inactivation of PON1 may lead to decrease in its antioxidant action against LDL oxidation. Our results suggest that an important component of the mechanism underlying this interaction may depend on estrogen's antioxidant effect and its preventive role in oxidative damage and lipid metabolism. This fact can suggest that the duration of treatment is important for the effect on oxidative stress and lipoprotein metabolism. HRT may be effective on oxidative stress and lipoprotein metabolism (PON1 and oxLDL) in estrogen deficiency.

In summary, the WHI (1996) trials suggest that estrogen alone does have advantages over estrogen plus progestin for treating postmenopausal women. Estrogen alone has only one or two adverse outcomes, increased strokes and probably pulmonary emboli, whereas the latter has increased strokes, CHD, pulmonary emboli, and breast cancer, and both regimens have an important benefit (less fractures). However, this riskbenefit assessment does not take into account the dementia findings, and even in their absence, estrogen alone produced no improvement in the overall global index. In addition, estrogen alone in women with a uterus increases the risk of endometrial cancer (Di Spiezio Sardo and Radhakrishnan, 2004) and incidence of vaginal bleeding, endometrial biopsy, and hysterectomy. Hence, our findings require further support in larger, placebo-controlled studies. Further studies are needed to assess the increased cardiovascular 
risk in menopause, which is associated with oxidative stress.

\section{References}

American Society of Hypertension (1992) Recommendations for routine blood measurement pressure by indirect cuff sphygmomanometry. Am. J. Hypertens., 5, 207-209.

Aviram, M., Rosenblat, M., Bisgaier, C.L., Newton, R.S., Primo-Parmo, S.L. \& La Du B.N. (1998) Paraoxonase inhibits high-density lipoprotein oxidation and preserves its functions. J. Clin. Invest., 101, 1581-1590.

Bittner, V. (1994) Hormonal treatment of postmenopausal women. N. Engl. J. Med., 331, 550.

Buege, J.A. \& Aust, S.D. (1978) Microsomal lipid peroxidation. Methods Enzymol., 52, 302-310.

Bureau, I., Laporte, F., Favier, M., Faure, H., Fields, M., Favier, A.E. \& Roussel, A.M. (2002) No antioxidant effect of combined HRT on LDL oxidizability and oxidative stress biomarkers in treated post-menopausal women. J. Am. Coll. Nutr., 21, 333-338.

Campos, H., McNamara, J.R., Wilson, P.W., Ordovas, J.M. \& Schaefer, E.J. (1988) Differences in low density lipoprotein subfractions and apolipoproteins in premenopausal and postmenopausal women. J. Clin. Endocrinol. Metab., 67, 30-35.

Colditz, G.A., Hankinson, S.E., Hunter, D.J., Willett, W.C., Manson, J.E., Stampfer, M.J., Hennekens, C., Rosner, B. \& Speizer, F.E. (1995) The use of estrogens and progestins and the risk of breast cancer in postmenopausal women. N. Engl. J. Med., 332, 1589-1593.

de Aloysio, D., Gambacciani, M., Meschia, M., Pansini, F., Bacchi Modena, A., Bolis, P.F., Massobrio, M., Maiocchi, G. \& Peruzzi, E. (1999) The effect of menopause on blood lipid and lipoprotein levels. The Icarus Study group. Atherosclerosis, 147, 147-153.

Di Spiezio Sardo, A. \& Radhakrishnan, S. (2004) Endometrial carcinoma on continuous combined HRT: case report and literature review. Maturitas, 48, 171-175.

Eaker, E.D., Chesebro, J.H., Sacks, F.M., Wenger, N.K., Whisnant, J.P. \& Winston, M. (1993) Cardiovascular disease in women. Circulation, $\mathbf{8 8}$, 1999-2009.

Ettinger, B. (1989) Overview of the efficacy of hormonal replacement therapy. Am. J. Obstet. Gynecol., 156, 1298-1303.

Friedewald, W.T., Levy, R.I. \& Frederickson, D.S. (1972) Estimation of the consentration of low- density lipoprotein cholesterol in plasma, without use of preparative ultracentrifuge. Clin. Chem., 18, 499-502.

Hasselwander, O., Savage, D.A., McMaster, D., Loughrey, C.M., McNamee, P.T., Middleton, D., Nicholls, D.P., Maxwell, A.P. \& Young, I.S. (1999) Paraoxonase polymorphisms are not associated with cardiovascular risk in renal transplant recipients. Kidney Int., 56, 289-298.

Itabe, H. (2003) Oxidized low -density lipoprotein: What is understood and what remains to be clarified. Biol. Pharm. Bull., 26, 1-9.

Kannel, W.B., Hjortland, M.C., McNamara, P.M. \& Gordon, T. (1976) Menopause and risk of cardiovascular disease. The Framingham study. Ann. Intern. Med., 85, 447-452.

Lazar, R.M., Connaire, K., Marshall, R.S., PileSpellman, J., Hacein-Bey, L., Solomon, R.A., Sisti, M.B., Young, W.L. \& Mohr, J.P. (1999) Developmental deficits in adult patients with arteriovenous malformations. Arch. Neurol., 56, 103-106.

Leal, M., Diaz, J., Serrano, E., Abellan, J. \& Carbonell, L.F. (2000) Hormone replacement therapy for oxidative stress in postmenopausal women with hot flushes. Obstet. Gynecol., 95, 804-809.

Lobo, R.A. (1990) Cardiovascular implications of estrogen replacement therapy. Obstet. Gynecol., 75, 18S-25S.

Mackness, M.I., Mackness, B., Durrington, P.N., Connelly, P.W. \& Hegele, R.A. (1996) Paraoxonase: biochemistry, genetics and relationship to plasma lipoproteins. Curr. Opin. Lipidol., 7, 69-76.

Mackness, M.I., Mackness, B. \& Durrington, P.N. (2002) Paraoxonase and coronary heart disease. Atheroscler, 3, 49-55.

Matthews, K.A., Meilahn, E., Kuller, L.H., Kelsey, S.F., Caggiula, A.W. \& Wing, R.R. (1989) Menopause and risk factors for coronary heart disease. N. Engl. J. Med., 321, 641-646.

Mendelson, M.E. \& Karas, H.D. (1999) The protective effective estrogen on the cardiovascular system. N. Engl. J. Med., 340, 1801-1820.

Nachtigall, L.E. (1990) Enhancing patient compliance with hormone replacement therapy at menopause. Obstet. Gynecol., 75, 77-80.

Nelson, M.D., Jr, Gonzalez-Gomez, I. \& Gilles, F.H. (1991) The search for human telencephalic ventriculofugal arteries. Am. J. Neuroradiol., 12, 215-222.

Oral, B. \& Özbaşar, D. (2003) The effect of sodium monofluorophosphate therapy on lipid and lipoprotein metabolism in postmenopausal women. Eur. J. Obstet. Gynecol. Reprod. Biol., 107, 
180-184

Rossouw, J.E., Anderson, G.L., Prentice, R.L., LaCroix, A.Z., Kooperberg, C., Stefanick, M.L., Jackson, R.D., Beresford, S.A., Howard, B.V., Johnson, K.C., Kotchen, J.M., Ockene, J. \& Writing Group for the Women's Health Initiative Investigators (2002) Risks and benefits of estrogen plus progestin in healthy postmenopausal women: principal results From the Women's Health Initiative randomized controlled trial. JAMA, 17, 321-333.

Ryan, K.R. (1976) Estrogens and atherosclerosis. Clin. Obstet. Gynecol., 19, 805-815.

Saha, N., Roy, A.C., Teo, S.H., Tay, J.S. \& Ratnam, S.S. (1991) Influence of serum paraoxonase polymorphism on serum lipids and apolipoproteins. Clin. Genet., 40, 277-282.

The Writing Group for the PEPI Trial (1995) Effects of estrogen or estrogen/progestin regimens on heart disease risk factors in postmenopausal women. The Postmenopausal Estrogen/ progestin Interventions (PEPI) Trial. J. Am. Med. Assoc., 274, 199-208.

The Writing Group for the PEPI Trial (1996) Effects of hormone replacement therapy on endometrial histology in postmenopausal women. JAMA, 275, 370-375.

Sutherland, W.H., Manning, P.J, de Jong, S.A., Allum, A.R., Jones, S.D. \& Williams, S.M. (2001) Hormone-Replacement Therapy Increases Serum Paraoxonase Arylesterase Activity in Diabetic Postmenopausal Women. Metabolism, 50, 319-324.

Van der Schouw, Y.T., van der Graaf, Y., Steyerberg, E.W., Eijkemans, J.C. \& Banga, J.D. (1996) Age at menopause as a risk factor for cardiovascular mortality. Lancet, 347, 714-718.

Warren, M.P. \& Halpert, S. (2004) Hormone replacement therapy: controversies, pros and cons) Best Pract. Res. Clin. Endocrinol. Metab., 18, 317-332. 